\title{
Rethinking Human Resource Strategies: A Shift in the Treatment of Contingent Workers
}

\author{
Tekeisha Zimmerman ${ }^{1}$, Mariya Gavrilova-Aguilar ${ }^{1}$ \& Princess Cullum $^{1}$ \\ ${ }^{1}$ College of Information, The University of North Texas, Denton, Texas, USA \\ Correspondence: Tekeisha Zimmerman, 3940 N. Elm Street, Denton, TX 76207, USA. Tel: 1-817-584-0773. \\ E-mail: zimmermantk@sbcglobal.net
}

Received: January 24, 2013

Accepted: February 16, 2013

Online Published: March 14, 2013

doi:10.5539/ijbm.v8n7p28

URL: http://dx.doi.org/10.5539/ijbm.v8n7p28

\begin{abstract}
Contingent workers fulfill valuable organizational needs and have functioned as knowledge resources for organizations. Despite their contributions, the literature suggests that a difference in treatment exists between contingent and standard workers in terms of onboarding, pay for performance, and training and development practices within organizations. This paper presents an empirically testable framework that argues for a shift in HR strategies that will allow for equality in treatment between standard and contingent workers within organizations.
\end{abstract}

Keywords: contingent worker, human resource development (HRD), treatment, training

\section{Introduction}

The American workforce has undergone significant changes over the past two decades. Increasing global competition and rising costs have forced organizations to modify their labor relationships in order to respond to changing market conditions (Broschak, Davis-Blake, \& Block, 2008; Yang, 2012). The increase of contingent workers, as part of organizational employment pools, represents one such modification. Research on contingent workers began appearing in the literature during the 1980s (Freedman, 1988; Williams, 1989). These workers are "employed because a company has an increased demand for a particular service or product or technology at a particular place at a specific time" (Freedman, 1988, p.1). Despite the consensus among researchers and practitioners that contingent workers fill a need (Boyce Ryan, Inus, \& Morgenson, 2007; Burgess \& Connell, 2006; Davis-Blake, Broschak, \& George, 2003), there is evidence regarding the negative impact of the employment of these workers on attitudes and work behaviors within organizations. A major source of these issues relates to the difference in treatment between contingent workers and standard employees (Boyce et al., 2007; Broschak et al., 2008; Padavic, 2005; Williams, 1989).

\section{Disparate Treatment between Contingent and Standard Workers}

Research suggests that the difference in treatment between contingent workers and standard workers within an organization can have powerful consequences on employee relationships. These consequences include perceptions of job security threat (Von Hippel, 2006; von Hippel \& Kalokerinos, 2012), lack of knowledge sharing between contingent and standard workers (Yang, 2012), and low organizational citizenship behaviors (OCB) (Van Dyne \& Ang, 1998). Prior research has extensively studied the difference in treatment between contingent workers and standard employees within organizations (Boyce et al., 2007; Broschak et al., 2008; Padavic, 2005; Williams, 1989). However, research on the impact of this difference on human resources (HR) strategies is lacking. Ashford, George, and Blatt (2007) argue that new theories and frameworks specifically aimed at non-standard workers are necessary because of the extreme differences in the workforce over the past few decades. The establishment of these new theories and frameworks for the evolving workforce is especially critical for HR professionals because they often own the task of providing strategic guidance on human capital issues. Thus, there is a need to examine how organizations should alter their HR strategies regarding contingent workers.

The purpose of this study is to offer a framework that argues for a shift in HR treatment towards contingent workers. Using Social Comparison Theory (Festinger, 1954) and Stigma Theory (Goffman, 1963), we examined the literature in three key areas of divergence in treatment: onboarding, pay for performance, and training and development. This led to the creation of a framework with empirically testable hypotheses. Finally, this 
manuscript provides implications for HR professionals regarding ways to successfully integrate contingent workers and recommends future research streams.

\subsection{Contingent Workers Defined}

Contingent employment was first defined by the U.S. Bureau of Labor Statistics in 1989 as "any job in which an individual does not have an explicit or implicit contract for long-term employment" (as cited in Szabó \& Négyesi, 2005). Connelly and Gallagher (2004) distinguished between four forms of contingent work: temporary staffing agencies, independent contractors, direct-hires, and seasonal employees. Because the term contingent worker is an omnibus term encompassing several employment arrangements, there are several terms associated with contingent workers found in the literature. Broschak et al., (2008) use the term nonstandard employee to distinguish between workers hired directly by the organization and workers hired for a contracted period of time. Burgess and Connell (2006) use the term temporary worker as it relates to HRM challenges in supporting organizations that employ short term contract workers. Despite the differing terms, one commonality between these studies is the assertion that different treatment of contingent and standard employees can lead to detachment from the organization. Burgess and Connell (2006) attribute lack of access to training, career development, and organizational identification as the main areas contributing to these differences.

For the purpose of this study, contingent workers are defined as "self-employed individuals who sell their services to client organizations on a fixed-term or a project basis" (Connelly \& Gallagher, 2004, p. 961). This definition covers contingent workers who are full-time, part-time, direct hires, temporary, or agency placed to fulfill a pre-determined need within an organization.

\section{Method}

To investigate the difference in treatment between contingent and standard workers, the researchers followed Torraco's (2005) integrative review method. Because reviewing HR strategies for contingent workers is an emerging topic, the goal of this literature review was to present a holistic synthesis of the literature to date that would support a new framework for future research. Peer-reviewed articles were collected from several databases including Google Scholar, EBSCO, ERIC and ProQuest. The search yielded 57 articles using the date range of January 1989 - October 2012 and combinations of the search terms contingent workers, contingent employees, HR strategies, social comparison, stigma and challenges. Abstracts for these57 articles were reviewed to determine if they discussed organizational challenges with contingent workers, social comparison or social stigma though the organizational lens and/or HR strategies related to contingent workers. 31 articles met these criteria and were used to formulate key ideas and themes related to our framework.

\subsection{Theoretical Frameworks}

\subsubsection{Social Stigma Theory}

Goffman (1963) introduced social stigma as a construct to examine how certain perceptions and biases arise, and explored the impact these perceptions and biases have on the stigmatized person in society. A stigmatized person is reduced "from a whole usual person to a tainted and discounted one" (Goffman, 1963, p. 3). Social stigma has traditionally been used to examine relationships among populations in the scientific realm (Byrne, 2000; Herek. 1999). However, in recent years, this theory has been examined in the organizational context (Yang et al., 2007). Yang (2012) examined stigma in the context of moral and social decision-making. The study concluded that stigmas threaten core tenants for human beings, but these areas can be changed with anti-stigma intervention. Because social stigma theory can help explain how those with a stigma are treated with bias, it is an appropriate lens to examine the treatment of contingent workers within organizations.

\subsubsection{Social Comparison Theory}

Festinger (1954) introduced social comparison theory as a method for individuals to determine perceived fairness. Social comparison drives self-evaluation and the need to compare one's own personal skills against others in a similar environment. In cases where the comparison results in extreme divergence, the need for comparison decreases because the evaluator feels there is no commonality. For example, an established professor in his field will not compare himself to a first year graduate student who is just entering the field. Although this may seem unimportant, in the case of contingent and standard workers it is a key point of divergence. These perceived differences can lead standard workers to devalue the output and worth of contingent workers because they simply do not believe they have comparable skills and abilities. Additionally, this could lead to invisible silos and a lack of teamwork which could be counterproductive to why contingent workers were hired.

Cuyper et al. (2007) reviewed outcomes between contingent and standard workers based on social contracts with 
organizations. The researchers concluded that contingent workers who felt they were not receiving the outcomes they deserved or that their role had a stigma attached to it could develop unfavorable attitudes towards and perform more poorly than standard employees. For these reasons, bias towards contingent workers must be explored and HR employees must consider moving towards more equality in treatment of this workgroup.

\subsubsection{Contingent Worker Advantages and Disadvantages}

Van Dyne and Ang (1998) suggested that contingent workers perform only the required duties and demonstrate low organizational citizenship behavior because of the perceived difference in treatment between them and permanent workers. Burgess and Connell (2006) further examined how the differences in treatment between contingent and permanent workers could lead to tension within the firm. In their study, both integration and separation strategies for the employment of contingent workers were empirically examined. Both strategy types posed issues and risks for the organization, but while integration strategies reduced flexibility, the quality of work produced by contingent workers increased. An increase in quality of work is a positive impact and suggests that a shift toward integration and equality in HR practices is needed.

Pfeffer (1994) concluded that "the biggest disadvantage of contingent employment arrangements is the difficulty in obtaining loyalty, dedication, or willingness to expend extra effort on behalf of the organization" (p. 24). In addition, having a contingent pool does not align with the needs for training and development, which can result in the lack of company-specific skills and a poorly trained contingent workforce. According to the US BLS, $7.4 \%$ of the U.S. workforce is comprised of self-employed or wage or salary-earning independent contractors, independent consultants, or freelance workers (as cited by Way, Lepak, Fay, \& Thacker, 2010). Using contingent workers may result in a negative effect on standard employee employment security, perceived organizational support (POS), commitment, loyalty, and retention (Davis-Blake et al., 2003; Wilkin, 2012). According to Way et al. (2010), using contingent workers to decrease labor costs may result in increased absenteeism and turnover of regular employees. Therefore, managers must clearly communicate the reasons for using contingent workers to regular employees to lessen concerns about job security. To minimize this disadvantage, HR must consider was to effectively integrate contingent workers into their permanent work pool. This integration does present a challenge to the HR field but the resulting benefits in dedication and work effort are expected to be seen immediately upon implementation of these changes.

\section{Contingent Worker Integration Framework and Hypotheses}

A key responsibility of HR employees is the management of human capital. Having a contingent workforce allows organizations to implement strategic changes more rapidly and efficiently; nevertheless, they must be hired in peripheral jobs instead of core functions (Hitt, Keats, \& DeMarie, 1998). Supporting this view, Pfeffer (1994) recommended that careful decisions were made on whether people would be the source of competitive advantage and the appropriate tasks for their roles. Based on this assertion, this section of the article presents key tenants used to create the framework and summarizes the relationship to the three identified variables: onboarding, pay for performance, and training and development.

\subsection{On Boarding}

Investment in permanent employees begins immediately upon hire. Most organizations have an onboarding process in place designed to orient new employees (D'Azurio, 2007). The onboarding process is a "holistic approach combining people, process and technology to optimize the impact a new hire has on the organization with an emphasis on both effectiveness and efficiency" (Frear, 2007, p. 4). Research on onboarding for contract workers is limited, but suggests that this group is not afforded the same integration efforts when joining an organization (Padvic, 2005). Onboarding is important because it introduces workers to the culture and expectations of the firm. It also provides an informal contract and sense of work stability between the employee and the firm. Contract workers fulfill a specific need at a point in time and their work represents the organization to the public. As such, they must align with the company's established mission, values, and goals. Thus it is hypothesized that:

H1: Lack of equivalent onboarding strategies between contingent and standard workers will result in low company culture knowledge for contingent workers.

\subsection{Pay for Performance}

Pay, money received for work or services completed, is a central component of HR strategy. Studies that examine pay structures between temporary and permanent workers show a difference in benefits and pay for performance (Hipple \& Stewart, 1996; Allan \& Sienko, 1997; Lautsch, 2003). This trend was seen early in the literature from a BLS study that demonstrated a difference of $\$ 3.72$ per hour between permanent and contract 
workers who performed the same role (Williams, 1989). Additionally, these workers are not typically given company benefits, which further widen the gap in pay. In a study of the petrochemical industry, contract workers received $60 \%$ less pay for performing the same work as permanent employees (Kochan, Smith, Wells \& Rebitzer, 1994).

In recent years, this gap in pay has closed and in some cases, contingent workers are paid a higher rate of pay than standard workers. This shift relates to the fact that in the past, contingent workers were more likely to be hired for low-skill roles like construction and extraction occupations (Way et al., 2010). In today's work environment, roles for contingent workers are more frequently in the areas of IT and managerial positions (Frauenhein, 2012). These studies demonstrated that differences in pay resulted in negative ramifications for the organization. Regardless of whether the pay rate is more favorable to contingent or standard workers, these findings should not be ignored by HR. Pay structures are frequently explored by organizations because negative feelings related to pay can lead to a difference in work output by employees. Thus, HR strategies must consider moving towards a more equality-based approach in pay structures for contingent workers. We assert that the payoff of higher commitment and increased quality of work are solid reasons to support the change in treatment. Therefore it is hypothesized that:

H2: Contingent workers who receive less pay for the same role will exhibit low organizational commitment. Likewise, if this is reversed and contingent workers receive higher wages than standard workers for the same role, disruption in cohesion between these work groups will arise.

\subsection{Training and Development}

In today's challenging economic environment, organizations increasingly rely on building and creating knowledge as a competitive advantage against their competition (Huber, 1991; Nonaka, 1994; Stinchcombe, 1990). Organizations must be able to create knowledge from within and outside their boundaries through acquisitions, partnerships, strategic alliances and contingent work (Matusik \& Hill, 1998). Training is one way that knowledge is created and disseminated throughout organizations. Training has also been shown to increase both affective commitment and organizational commitment, but it is often reserved for standard workers only (Chambel \& Sobral, 2011). Chambel \& Sobral (2011) argue that when contingent workers are allowed to participate in training activities, they tend to perceive higher organizational support, which leads to increased loyalty.

Both Chambel \& Sobral (2011) and Matusik (1998) successfully argued that contingent workers are a source of knowledge for organizations and that training is a major source for obtaining this knowledge. Stigmas and social comparison barriers can hinder the ability for sharing post-class. Therefore it is hypothesized that:

H3: Knowledge sharing between contingent and standard workers is low in organizations where contingent workers are not included in training and development events.

H4: Contingent workers will exhibit low organizational commitment when there is a lack of knowledge sharing between them and standard workers. 


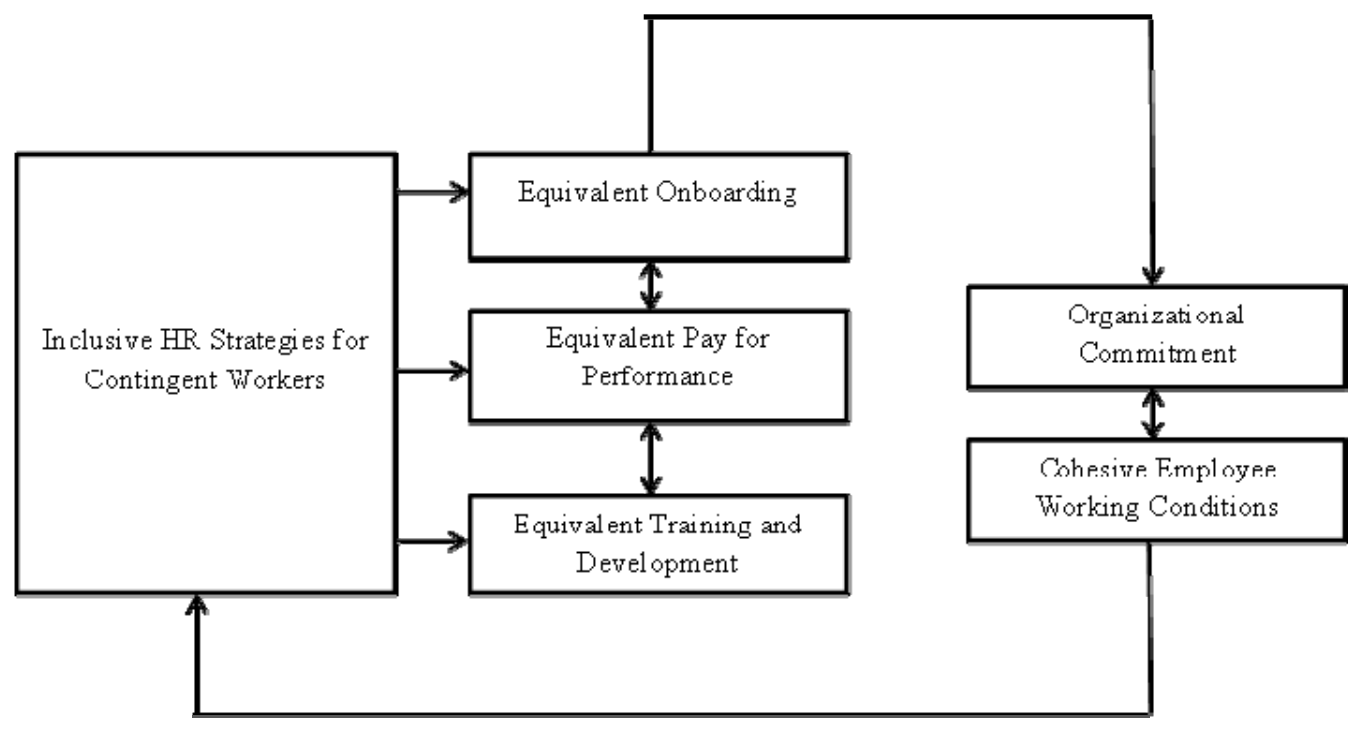

Figure 1. Contingent worker integration framework

\section{Discussion}

The present literature calls for research on the mechanisms and processes through which firms are able to create conditions conducive to the integration and combination of knowledge from different functional and disciplinary domains, as well as outside the traditional boundaries. Specifically, some scholars argue that contingent work affects an organization's abilities to accumulate knowledge, create value, and establish competitive advantage (Matusik \& Hill, 1998). To address these concerns, future research is necessary in a few key areas. First, research on onboarding practices for contingent workers is needed because onboarding has been shown to increase organizational commitment among employees. In today's environment, contingent workers are often placed directly into the work environment without the benefit of learning about cultural aspects of the organization. This onboarding is necessary to enhance knowledge of organizational goals and create cohesiveness between contingent and standard workers. Second, future research is needed to understand all human resource practices related to the contingent workforce. This paper has examined three key areas, but further examination of organizational practices is necessary to create a holistic view. Finally, future research should test the framework put forth in this paper. Testing is necessary to operationalize the model so that further insight into organizational dynamics that affect contingent workers can be examined.

\section{Conclusion}

The various forms of contingent work arrangements differ in both contractual provisions and contextual factors (Connelly \& Gallagher, 2004). Because contingent workers use their skills in numerous organizational settings, their depth of knowledge about public skills (e.g. industry and occupational best practices) is more developed than traditional employees (Matusik \& Hill, 1998). This research furthers that argument by asserting that a difference in treatment can act as a barrier to the sharing of knowledge between standard and contingent workers in the organization. To overcome this barrier, HR structures that directly lead to this difference in treatment must be shifted if organizations are to maximize these workers. Morrow (1993) suggests that organizations perceive contingent work as just, if not, more valuable than traditional resources of the organization. Thus, our goal is to make a contribution to the literature by formally addressing the need for HR to onboard, pay, and develop their contingent workers equally. Thus, effectively and efficiently maximize their knowledge, which is relevant to both theory and application. The first step is examination of current practices and an understanding of current attitudes and work behaviors between contingent and standard workers.. Initially, this may be a huge undertaking by HR employees. As research suggests, the long term payoff can be a more cohesive workgroup and employees who are highly committed to the organization regardless of their work classification.

\section{References}

Allan, P., \& Sienko, S. (1997). A comparison of contingent and core workers' perception of their jobs' characteristics and motivational properties. SAM Advanced Management Journal, 62(3), 4-9.

Ashford, S. J., George, E., \& Blatt, R. (2007). The opportunities and challenges of research on nonstandard employment. The Academy of Management Annals, 1, 65-117. http://dx.doi.org/10.1080/078559807 
Boyce A. S., Ryan, A. M., Inus, A. L., \& Morgenson, F. P. (2007). Temporary worker, permanent loser? A model of the stigmatization of temporary workers. Journal of Management, 33, 5-29. http://dx.doi.org/10.1177/0149206306296575

Broschak, J. P., Davis-Black, A., \& Block, E. S. (2008). Nonstandard, not substandard: The relationship among work arrangements, work attitudes, and job performance. Work and Occupations, 35(1), 3043. http://dx.doi.org/10.1177/0730888407309604

Burgess, J., \& Connell, J. (2006). Temporary work and human resources management: issues, challenges and responses. Personnel Review, 35(2), 129-140. http://dx.doi.org/10.1108/00483480610645786

Byrne, P. (2000). Stigma of mental illness and ways of diminishing it. Advances in Psychiatric Treatment, 6(1), 65-72. http://dx.doi.org/10.1192/apt.6.1.65

Chambel, M. J., \& Sobral, F. (2011). Training is an investment with return in temporary workers: A social exchange perspective. Career Development International, 16, 161-177. http://dx.doi.org/10.1108/13620431111115613

Connelly, C. E., \& Gallagher, D. G. (2004). Emerging trends in contingent work research. Journal of Management, 30, 959-983. http://dx.doi.org/10.1016/j.jm.2004.06.008

Cuyper, N. D., De Jong, J., De Witte, H., Isakssom, K., Rigotti, T., \& Schalk, R. (2007). Literature reviews of theory and research on the psychological impact of temporary employment: Towards a conceptual model. International Journal of Management Reviews, 9(4), 1-27.

D'Aurizio, P. (2007). Onboarding: Delivering the promise. Nursing Economics, 25(4), 228-229.

Davis-Blake, A., Broschak, J. P., \& George, E. (2003). Happy together? How using nonstandard workers affects exit, voice, and loyalty among standard employees. Academy of Management Journal, 46, 475-485. http://dx.doi.org/10.2307/30040639

Festinger, L. (1954). A theory of social comparison processes. Human Relations, 7, 117-140. http://dx.doi.org/10.1177/001872675400700202

Frauenheim, E. (2012, August 3). Contingent workers: Whey employers must make them feel welcome. Workforce Management, 34-39. Retrieved from http://www.workforce.com/article/20120803/NEWS02/120809979/contingent-workers-why-companies-m ust-make-them-feel-valued

Frear, S. (2007). Comprehensive onboarding, traction to engagement in 90 days. Washington, DC: Human Capital Institute.

Freedman, A. (1988). How the 1980's have changed industrial relations. Monthly Labor Review, 111, 35-38.

Goffman, E. (1963). Stigma: Notes on the management of spoiled identity. New York: Prentice-Hall.

Herek, G. (1999). AIDS and stigma. American Behavioral Scientist, 42, 1106-1116.

Hipple, S., \& Stewart, J. (1996). Earnings and benefits of workers in alternative work arrangements. Monthly Labor Review, 119, 46-54.

Hitt, M. A., Keats, B. W., \& DeMarie, S. M. (1998). Navigating in the new competitive landscape: Building strategic flexibility and competitive advantage in the 21st century. The Academy of Management Executive, 12, 22-42.

Huber, G. P. (1991). Organizational learning: The contributing processes and the literatures. Organization Science, 2, 88-115. http://dx.doi.org/10.1287/orsc.2.1.88

Kochan, T. A., Smith, M., Wells, J. C., \& Rebitzer, J. B. (1994). Human resource strategies and contingent workers: The case of safety and health in the petrochemical industry. Human Resource Management, 33(1), 55-78. http://dx.doi.org/10.1287/orsc.2.1.88

Lautsch, B. A. (2003). The influence of regular work systems on compensation for contingent workers. Industrial Relations: A Journal of Economy and Society, 42, 565-588. http://dx.doi.org/10.1111/1468-232X.00307

Matusik, S. F., \& Hill, C. W. L. (1998). The utilization of contingent work, knowledge creation, and competitive advantage. Academy of Management Review, 23, 680-697. http://dx.doi.org/10.2307/259057

Morrow, L. (1993, March). The temping of America. Time Magazine, 40-41. Retrieved from 
http://www.timemagazines.com

Nonaka, I. (1994). A dynamic theory of organizational knowledge creation. Organization Science, 5, 14-37. http://dx.doi.org/10.1287/orsc.5.1.14

Padvic, I. (2005). Laboring under certainty: Identity renegotiation among contingent workers. Symbolic Interaction, 28(1), 111-134. http://dx.doi.org/10.1525/si.2005.28.1.111

Pfeffer, J. (1994). Competitive advantage through people. California Management Review, 36, 9-28. http://dx.doi.org/10.2307/41165742

Stinchcombe, A. L. (1990). Information and organizations. Berkeley, CA: University of California Press.

Szabo, K., \& Negysei, A. (2005). The spread of contingent work in the knowledge-based economy. Human Resource Development Review, 4, 63-85. http://dx.doi.org/10.1177/1534484304274073

Torraco, R. J. (2005). Writing integrative literature reviews: Guidelines and examples. Human Resource Development Review, 4, 356-367. http://dx.doi.org/10.1177/1534484305278283

Van Dyne, L., \& Ang, S. (1998). Organizational citizenship behavior of contingent workers in Singapore. Academy of Management Journal, 41, 692-703. http://dx.doi.org/10.2307/256965

Von Hippel, C. (2006). When people would rather switch than fight: Out-group favoritism among temporary employees. Group Processes \& Intergroup Relations, 9, 533-546. http://dx.doi.org/10.1177/1368430206067556

Von Hippel, C., \& Kalokerinos, E. K. (2012). When temporary employees are perceived as threatening: Antecedents and consequences. Leadership and Organizational Development Journal, 33, 200-216. http://dx.doi.org/10.1108/01437731211203483

Way, S. A., Lepak, D. P., Fay, C. H., \& Thacker, J. W. (2010). Contingent workers' impact on standard employee withdrawal behaviors: Does what you use them for matter? Human Resource Management, 49, 109-130. http://dx.doi.org/10.1002/hrm.20336

Wilkin, C. L. (2012). I can’t get no satisfaction: Meta-analysis comparing permanent and contingent workers. Journal of Organizational Behavior, 1, 1-18.

Williams, H. B. (1989, March). What temporary workers earn: Findings from new BLS study. Monthly Labor Review, 3-112.

Yang, L. H., Kleinman, A., Link, B. G., Phelan, J. C., Lee, S., \& Good, B. (2007). Culture and stigma: Adding moral experience to stigma theory. Social Science and Medicine, 64, 1524-1535. http://dx.doi.org/10.1016/j.socscimed.2006.11.013

Yang, X. (2012). Contingent workers, permanent loser? How perceived trust shapes communication between contingent workers and standard workers in knowledge-based organizations. International Journal of Business and Social Science, 3, 172-180. 